\title{
安徽庐江三里同北北东向动力变质带内 白云母的研究
}

王小风季继中

(中国地质科学院地质力学研究所, 北京)

在前人对白云母研究的基础上 ${ }^{[1-4]}$, 笔者仅就欵庐断裂带内庐江三里同北北东向动力变质 带的白云母特征作以下探讨.

\section{一、一般地质概况}

安微庐江三里同动力变质带出露于庐江西三公里庐江一合肥公路上(图 1), 处于邩庐断裂 主带所在部位,呈北北东向条带状伸延,向北可达张八岭一带, 向 南潜山野人寨也可见及. 它主要由一套云母石英片糜岩及后期叠 加的碎裂变质岩所组成，可见宽度 90 余米，其主要矿物成分有： 石英、低温中长石,多硅白云母及少量钾长石.

\section{二、多硅白云母的实验研究}

1. 硅白云母的光学特征在显微镜下多硅白云母呈细鳞 片状及叶片状，夹在相对脆性的石英或长石透镜体之间,组成塑性 条带定向产出. 其粒径一般在 0.1一 $0.2 \mathrm{~mm}$ 左右. 后期变形构造 发育,如可见扭折构造,并呈 “ $\mathrm{S}$ ” 形或波纹状弯曲.

由于白云母 $\mathrm{KAl}_{2}\left(\mathrm{Si}_{3} \mathrm{AlO}_{10}\right)(\mathrm{OH})_{2}$ 和绿鳞石 $\mathrm{K}\left(\mathrm{Mg}, \mathrm{Fe}^{2+}\right)$ $\left(\mathrm{Al}, \mathrm{Fe}^{3+}\right) \mathrm{Si}_{4} \mathrm{O}_{10}(\mathrm{OH})_{2}$ 可以组成有限的类质同象系列，而形成多 硅白云母 ${ }^{[3]}$. 因此多硅白云母与白云母在很多光学特征上是相同 的, 但以多硅白云母的光轴角一般小于 $35^{\circ}$ 做为区别二者的重要 标志. 在该变质带内有两种多型的多硅白云母存在, 即 $3 \mathrm{~T}$ 型和 $2 \mathrm{M}$ 型,它们常常共生在一起, 可是在光性上却有不同:（1）3T 型 多硅白云母的（001）解理面，于正交偏光下永远是消光的；(2)

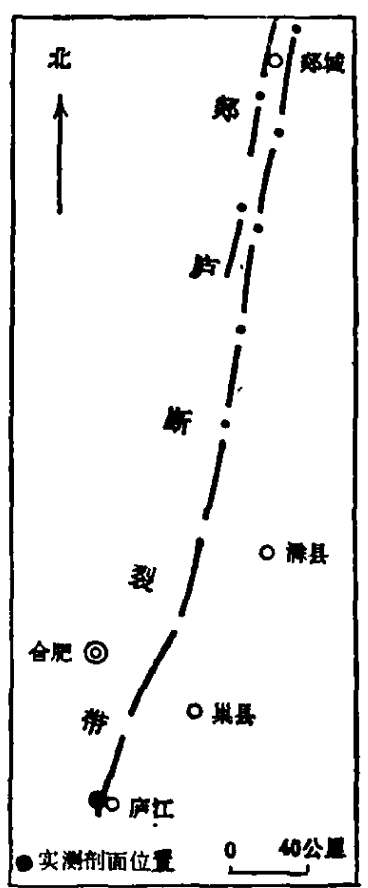

图 1 安徽庐江三里同动 力变质带实测剖面位置图 $3 \mathrm{~T}$ 型多硅白云母, $2 \mathrm{~V} \cong 0^{\circ}$. 一般情况下, 在这片糜岩内 $3 \mathrm{~T}$ 型所占比例较大, 同时 $3 \mathrm{~T} /(3 \mathrm{~T}+$ $2 \mathrm{M}$ ). 随着所处构造部位不同也有所变化. 如表 1 所示在北北东向断面上及挤医扁豆体内 $3 \mathrm{~T} /(3 \mathrm{~T}+2 \mathrm{M})$ 较高(前四个数据), 大多数在 0.90-0.99 之间,但于断层面旁侧该值减小 (后 三个数据), 为 $0.46-0.53$. 显然, 这是由于应力在断裂面附近集中, 使 $2 \mathrm{M}$ 型多硅白云母几乎 全部转变为 $3 \mathrm{~T}$ 型多硅白云母.

本文 1981 年 12 月 18 日收到。 
表 1 多硅白云母结构类型变化

\begin{tabular}{c|c|c|c|c|c|c|c}
\hline 样品号 & $3309-11$ & $3309-11-6$ & $3309-11-7$ & $3309-12$ & $3309-6-1$ & $3309-6-4$ & $3309-14-4$ \\
\hline $3 \mathrm{~T} /(3 \mathrm{~T}+2 \mathrm{M})$ & 0.98 & 0.67 & 0.99 & 0.90 & 0.53 & 0.50 & 0.46 \\
\hline
\end{tabular}

2. 多硅白云母的筑热分析笔者对该变质带内的四个样品做了差热分析，其结果与叶 大年同志所作 3T 型多硅白云母差热曲线对比极为相似 ${ }^{\left[{ }^{6]}\right.}$ ，即差热曲线的两个吸热效应均在

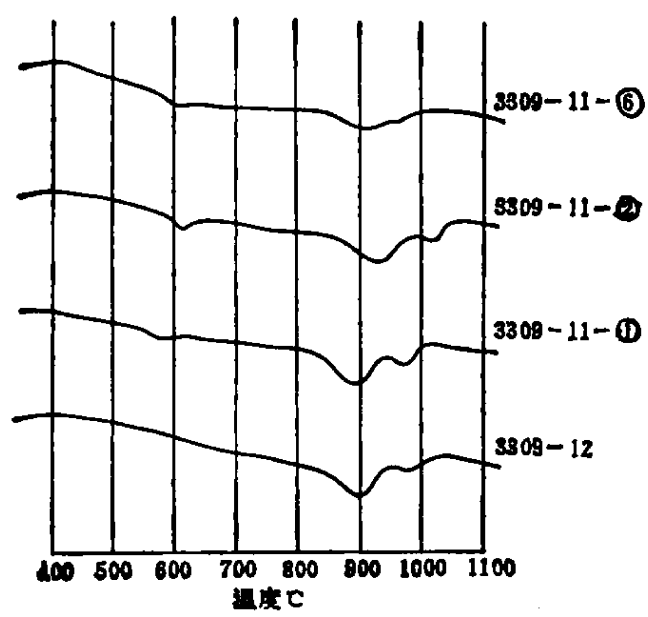

图 2 多硅白云母差热曲线 $1000^{\circ} \mathrm{C}$ (或 $1050^{\circ} \mathrm{C}$ ) 以前出现. 这与 $2 \mathrm{M}$ 型白云 母通常在 $1050^{\circ} \mathrm{C}$ 以前只有一个吸热效应 $\left(850^{\circ} \mathrm{C}\right.$ $9000^{\circ} \mathrm{C}$ 左右)，第二个吸热效应则在 $1050^{\circ} \mathrm{C}$ 以上(或 $1100{ }^{\circ} \mathrm{C}$ 左右)的特征截然不同(图 2).

3. 多硅白云母的X讨线粉末分析 对该变质 带内 20 余个样品进行 $X$ 射线分析的结果如下:

（1）把采自断裂面上的样品 (3309-11、12) 的 $\mathrm{X}$ 射线粉末图与 $1 \mathrm{M} 、 2 \mathrm{M}$ 型白云母粉末图 (Yoder 等 1955）相比较后发现，缺少 $d=3.00,3.21,3.50$, $3.97,4.30$ 的谱线, 但与 $3 \mathrm{~T}$ 型白云母相比较则数据 是非常接近的 ${ }^{[7]}$, 因此确定其为 3T 型多硅白云母.

（2）Sassi 等人研究了泥质变质岩中钾质白云母 后发现白云母 $b_{0}$ 值随着变质作用压力类型增高而加大, 从而指出 $b_{0}$ 值可以作为地质压力计, 并建议以岩石中白云母 $b_{0}$ 值 $9.000 \AA, 9.040 \AA$ 做为界限, 将变质作用划分为低、中、高三种压 力类型 ${ }^{[8]}$. 我们把庐江动力变质带内 19 个样品用 $X$ 光粉末衍射法分析的结果列于表 2 . 从表 2 看 出, 该带 $b_{0}$ 值皆大于 $9.000 \AA$, 示为多硅白云母. 按琞 Sassi 等提出的原则, 可将所测 $b_{0}$ 值分为两 组: 第一组 $b_{0}$ 值在 9.012-9.039 之间, 属中压 型.（表 2 第 $11-19$ 个样品); 第二组 $b_{0}$ 值在

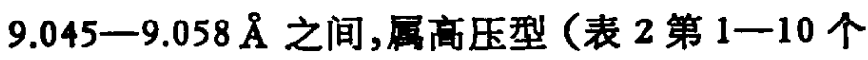
样品). 造成这两组数据差异性的原因是炏庐断 裂带的活动导致应力在断裂面附近集中，促使多 硅白云母 $b_{0}$ 值加大 (大部分已是 $3 T$ 型多硅白云 母).

\section{4. 多珪白云母的红外光请分析 笔者选用} 3309-11，3309-12，3309-11-4 及 3309-11-6 样 品进行红外光谱分析, 结果见图 3. 由此得知多 硅白云母的红外光谱特征是:（1）上述样品的红 外光谱与 Wellenzahlen 标准谱对比看出,它们都 具层状硅酸盐云母族的共同特点： $\mathrm{OH}$ 基伸缩振 动峰位于 $3400-3700 \mathrm{~cm}^{-1}$, 弯曲振动位于 $600-$

表 2 多硅白云母 $b_{0}$ 值

\begin{tabular}{|c|c|c|}
\hline 样品䒓 & $b_{0}(\AA)$ & 采样部位 \\
\hline $3309-11-2(1)$ & 9.0580 & \multirow{10}{*}{$\begin{array}{l}\text { 承庐断裂带 } \\
\text { 主断面 }\end{array}$} \\
\hline $3309-11-2(2)$ & 9.0580 & \\
\hline $3309-11-6$ & 9.0396 & \\
\hline $3309-11-7 @$ & 9.0513 & \\
\hline $3309-12-1(1)$ & 9.0513 & \\
\hline $3309-12-1 @$ & 9.0457 & \\
\hline $3309-13-4$ & 9.0526 & \\
\hline $3309-13-5$ & 9.0526 & \\
\hline $3309-14-3$ & 9.0250 & \\
\hline $3309-14-4$ & 9.0512 & \\
\hline $3309-6-1$ & 9.0213 & \multirow{9}{*}{$\begin{array}{l}\text { 都庐断至带 } \\
\text { 主断面旁饱 }\end{array}$} \\
\hline $3309-6-2$ & 9.0122 & \\
\hline $3309-6-3$ & 9.0224 & \\
\hline $3309-6-4$ & 9.0292 & \\
\hline 油-B & 9.0370 & \\
\hline 油-B, & 9.0396 & \\
\hline 油-B。 & 9.0158 & \\
\hline 油-B $B_{10}$ & 9.0120 & \\
\hline 油-B & 9.0186 & \\
\hline
\end{tabular}
$900 \mathrm{~cm}^{-1}$; 硅酸盐阴离子团 $\mathrm{Si}-\mathrm{O}$ 伸缩振动位于 $700-1200 \mathrm{~cm}^{-1}$, 弯曲振动位于 $150-600 \mathrm{~cm}^{-1}$. 
但 $\mathrm{OH}$ 基弯曲振动的吸收峰和 $\mathrm{Si}-\mathrm{O}$ 弯曲振动的吸收峰数目较多, 可能为多硅白云母所特有的 谱带到. (2) 上述样品的红外光谱有着明显不同. 主要表现在 $\mathrm{OH}$ 基伸缩振动吸收峰的强度 上, 前两个样品比后两个样品强度大, 可能由于这两类样品产出的构造部位不同所致,因断裂 活动的影响引起多硅白云母的 $\mathrm{OH}$ 基伸缩振动的差异.

(a)

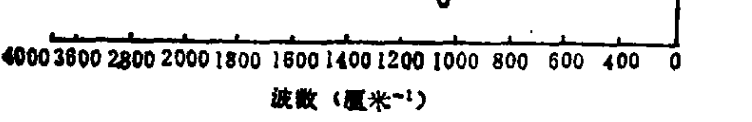

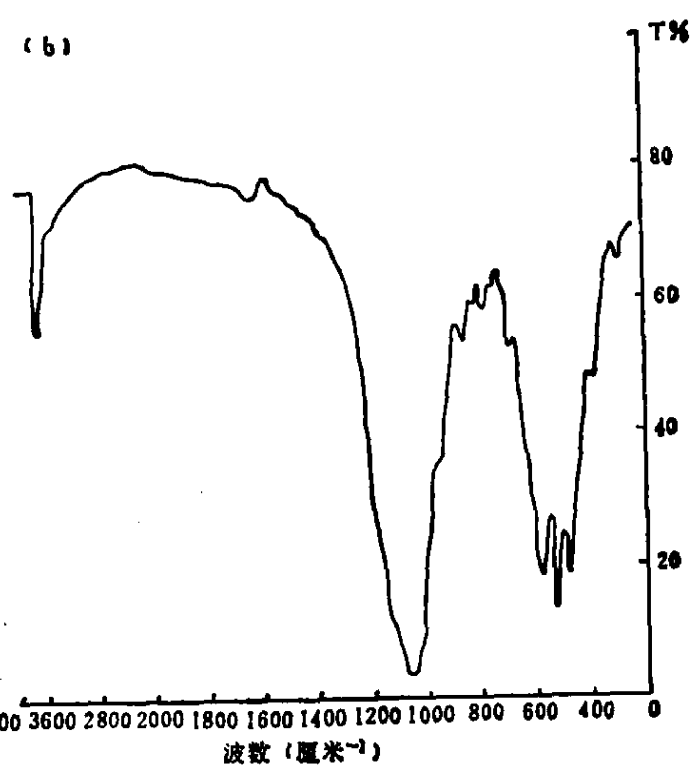

图 3 多硅白云母的红外吸收光谱

（a）样品3309-12；（b）样品3309-11-4

表 3 多硅白云母的电子探针分析资料

\begin{tabular}{|c|c|c|c|c|c|c|c|c|c|}
\hline 样占 & $3309-12$ & $3309-11$ & $3309-11-4$ & $309-11-6$ & $\begin{array}{l}\text { 晶体结构 } \\
\text { 式中数 }\end{array}$ & $3309-12$ & $3309-11$ & $|3309-11-4|$ & $3309-11-6$ \\
\hline $\mathrm{Na}_{2} \mathrm{O}$ & 0.17 & 0.08 & 0.09 & 0.08 & $\mathrm{Na}$ & 0.02 & 0.01 & 0.01 & 0.01 \\
\hline $\mathrm{MgO}$ & 4.94 & 3.79 & 4.02 & 4.30 & $\mathrm{Mg}$ & 0.49 & 0.38 & 0.40 & 0.43 \\
\hline $\mathrm{Al}_{2} \mathrm{O}_{3}$ & 22.39 & 23.05 & 23.37 & 23.19 & Al & 1.75 & 1.84 & 1.85 & 1.83 \\
\hline $\mathrm{SiO}_{2}$ & 50.56 & 50.67 & 50.44 & 51.50 & $\mathrm{Si}$ & 3.35 & 3.42 & 3.39 & 3.44 \\
\hline $\mathrm{K}_{2} \mathrm{O}$ & 12.35 & 12.21 & 11.88 & 12.12 & K & 1.05 & 1.05 & 1.02 & 1.03 \\
\hline $\mathrm{CaO}$ & 0.10 & 0.09 & 0.07 & 0.03 & $\mathrm{Ca}$ & 0.01 & 0.01 & 0.01 & 0.002 \\
\hline $\mathrm{TiO}_{2}$ & 0.10 & 0.07 & 0.06 & 0.03 & $\mathrm{Ti}$ & 0.01 & 0.004 & 0.003 & 0.002 \\
\hline $\mathrm{FeO}$ & 5.93 & 5.09 & 5.51 & 4.71 & $\mathrm{Fe}$ & 0.33 & 0.29 & 0.31 & 0.26 \\
\hline
\end{tabular}

5. 电子探针显微分析从表 3 看出, 该变质带白云母中 $\mathrm{SiO}_{2}$ 的含量均大于 $50 \%$,结构 式中 $\mathrm{Si}-3.35-3.44$, 平均为 3.40, 是典型的多硅白云母, 这与美国佛兰西斯堪、日本三波 川、我国信阳等变质带的多硅白云母的化学成分十分相似 ${ }^{[6]}$. 但庐江变质带内 $\mathrm{Mg}$ 含量较高, 在 0.38一 - 0.49 之间, 平均为 0.42. 多硅白云母中 $\mathrm{Mg}$ 的含量随着压力增高而增加,因此它可以 反映其形成时的压力. 图 4 展示了庐江动力变质带 $\mathrm{Mg}$ 的含量与美国佛兰西斯堪变质带 $\mathrm{Mg}$ 的含要相近，说明这两个变质带形成时的压力较世界其他各变质带都大. 


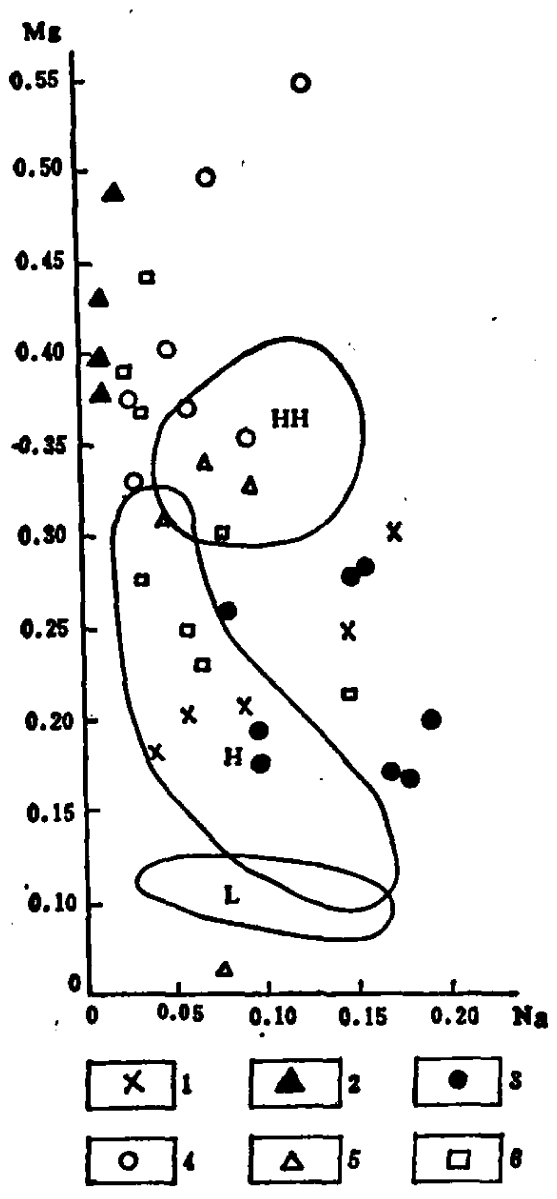

图4 多硅白云母中 Mg 量和压力的关系 (据 Cipriani)

1. 作阳变质制多硅白云母; 2. 古江动力变质带多硅 白云母；3. 三波川变质带多硅白云母；4，俈兰西 斯塔变质德冬硅白云母; 5. 新路里多尼亚变质带多 硅白云母；6. 阿尔果斯变质带多硅白云母

\section{三、讨 论}

1. 前面就安徽庐江三里同动力变质带内的 白云母采用了多种方法分析,其结果十分吻合. 从化学成份、多型和光学性质都一致反映该变 质带内的白云母为 3T 型多硅白云母，系典型 的低温高压型矿物, 进而证实上述变质带为低 温高压型动力变质带.

2. 构造应力是导致 3T 型多硅白云母 产生 的主导因素. 主要表现在:（1）宏观上庐江三 里同低温高压型动力变质带与鄭庐断裂带的展 布具有一致性.（2）微观上产于不同构造部位 的多硅白云母的结构状态存在明显差异。接近 犯庐断裂带主断面的部位，3T 型多硅白云母 的比例变大, $3 \mathrm{~T} /(3 \mathrm{~T}+2 \mathrm{M})$ 趋于 $1.0, b_{0}$ 值 (或 $a_{0} \sqrt{3}$ ) 值也加大, $2 \mathrm{M}$ 型几乎完全转 变 为 3T 型. 此外,红外光谱谱带也有变异. 这样就 不难得出，构造应力不但可以使岩石矿物发生 各种形变,而且还可以使地球化学元素迁移,导 致岩石矿物的化学成分发生变化，以及矿物的 结构状态、光学性质的改变，这是实现 $3 \mathrm{~T}$ 型多 硅白云母转变的重要机制.

3. 该动力变质带内的岩石至少经历了两期 变质作用。早期（元古代?）形成了云母石英片 岩组成的中医变质带, 晚期(中生代以来)又与 级庐断裂活动相伴的低温高压动力变质带迭加之. 这与多硅白云母的演化特征是一致的.早期 变质作用形成的白云母 $b_{0}$ 值在 9.012-9.039 之 之间 (或更低些)，以 $2 \mathrm{M}$ 型为主. 晚期由于动 力变质作用的迭加改造,使多硅白云母 $b_{0}$ 值增至 9.045一- $9.058 \AA$ 之间,并以 $3 \mathrm{~T}$ 型为主.

致谢: 在本项研究工作中曾得到中国地质科学院地质力学研究所王治顼、刘兆盛、须湘官同志，矿床研究 所部立韧同志和治金部桂林地质研究所郑号荣同志, 中国科学院地质研究所张振属同志的帮助，在本文修改 过程中还得到叶大年同志的指导与鼓励,在此一并表示致谢.

[1] Kikara, K., Matsumoto, T. \& Banno, S., Min. Mag., 40(1975), 202-204.

[2]王憘荫, 应力矿物篗论, 地质出版社, 1978, 88-89.

[3] 叶大年等,科学通报, 24(1979), 5: 217-218。

[4] 张旗等,地质科学, 1980, 4: 340-346.

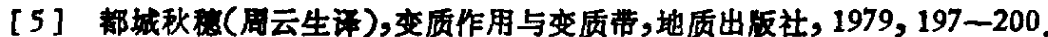

[6]中国科学院地质研究所等,华北断块区的形成与发展,科学出版社. 1980, 122-126.

[7]叶大年等,岩破实哭室工作方法,地质出版社. 1981，259-260。

[8] 张旗等,科学通报, 24(1979), 3: 120-123.

[9] 本幻粚,地质科学, 1979, 3; 276-278。 